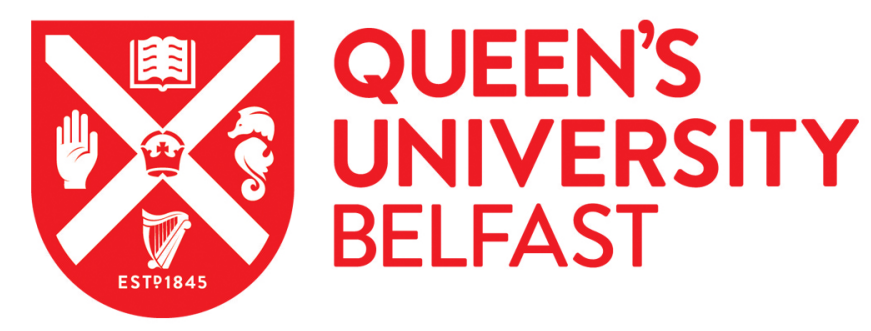

\title{
Teachers' self-perceptions of mathematical knowledge for teaching at the transition between primary and post-primary school
}

O'Meara, N., Prendergast, M., Cantley, I., Harbison, L., \& O'Hara, C. (2020). Teachers' self-perceptions of mathematical knowledge for teaching at the transition between primary and post-primary school. International Journal of Mathematical Education in Science and Technology , 51(4), 497-519.

https://doi.org/10.1080/0020739X.2019.1589004

Published in:

International Journal of Mathematical Education in Science and Technology

\section{Document Version:}

Peer reviewed version

Queen's University Belfast - Research Portal:

Link to publication record in Queen's University Belfast Research Portal

Publisher rights

Copyright 2019 T \& F. This work is made available online in accordance with the publisher's policies. Please refer to any applicable terms of use of the publisher.

\section{General rights}

Copyright for the publications made accessible via the Queen's University Belfast Research Portal is retained by the author(s) and / or other copyright owners and it is a condition of accessing these publications that users recognise and abide by the legal requirements associated with these rights.

Take down policy

The Research Portal is Queen's institutional repository that provides access to Queen's research output. Every effort has been made to ensure that content in the Research Portal does not infringe any person's rights, or applicable UK laws. If you discover content in the Research Portal that you believe breaches copyright or violates any law, please contact openaccess@qub.ac.uk. 


\begin{abstract}
The school system in both the Republic of Ireland [ROI] and Northern Ireland [NI] is configured to accommodate children into discrete educational bands at different stages on their learning journey. Research has consistently shown that the transition from primary to postprimary, which typically occurs between the ages of 11 and 13, is the most challenging transition with the negative effects more pronounced for mathematics than any other subject. This cross-border study investigates this transition in mathematics education from the final year of primary school to first year of post-primary school from the perspective of teachers involved with these year groups. It examines teachers' knowledge of the mathematics curriculum and teaching strategies employed in the other phase. The majority of primary teachers reported being unfamiliar with the curriculum and teaching approaches employed in the first year of post-primary and the differences between the two jurisdictions were not significant. However, a difference was noted in the responses of second level teachers. Teachers in NI appeared more confident in their knowledge of the curriculum and teaching approaches adopted in the final year of primary school than their ROI colleagues. In this paper, the authors will elaborate on these findings; outline possible reasons for the differences across jurisdictions and share what impact teacher knowledge is having on classroom practices.
\end{abstract}

\title{
Introduction
}

Internationally, the transition from primary to post-primary education is one of the greatest challenges that young people experience during the entire time spent in formal education. This transition, which typically occurs between the ages of eleven and thirteen, is deemed to play a central role in academic performance, well-being, and the mental health of the individual [1]. It presents a significant challenge with lasting effects on the educational career of the student [2]. The challenges presented by this transition are multifaceted [3]. Barber [4] describes the transition as a set of five hurdles comprising bureaucratic, social and emotional, curriculum, pedagogy, and management of learning, all of which must be overcome simultaneously. In addition to this, Evangelou et al. [5, p.2] conducted a study in England to investigate factors that contribute to a successful transition for children and ascertain that:

“...developing new friendships and improving their self-esteem and confidence; having settled so well in school life that they caused no concerns to their parents; showing an 
increasing interest in school and school work; getting used to their new routines and school organisation with great ease [and] experiencing curriculum continuity."

As demonstrated, the majority of research conducted into what constitutes effective transition refers primarily to curriculum and pedagogical continuity. Likewise, research conducted in the area of problematic transitions all point to a lack of continuity in this regard [7-8].

Although the transition from primary to post-primary education can cause a decline in student achievement and attitudes across a range of subject areas, existing literature indicates that mathematics is often one of the subjects most affected [9-11]. Research has shown that the transition from primary to post-primary mathematics education can result in a significant decline in students' academic performance, confidence, interest and liking for the subject, leading to disengagement and reduced levels of self-confidence and motivation [13-14]. Furthermore, Bicknell et al. [3] found that the gap between high achieving and low achieving students widened significantly during the transition period in this subject area while Hernandez-Martinez et al. [10] found that the impact of different educational transitions was more profound for weaker students as they progress from primary through to third level education. Attard [13] investigated students' experiences of the transition from primary to postprimary mathematics education in Australia. She listed curriculum, pedagogy, assessment strategies, social interactions and students' relationships with others as key factors that dictate the success of transition. Likewise, Galton et al. [15] found that teachers' lack of knowledge of what students had already covered in primary school led to a negative feeling among students regarding needless repetition and lack of curricular progress. This contributed to an ineffective transition from primary to post-primary mathematics. As was the general case, these researchers concluded that content and pedagogical continuity played a significant role in determining the effectiveness of the transition from primary to post-primary mathematics education. 
Building on these findings, this particular study analyses the levels of knowledge (in domains pertinent to transition) that teachers, in Northern Ireland (NI) and the Republic of Ireland (ROI), at both sides of the transition, possess and the impact that this knowledge can have on the transition. The work of Putnam \& and Borko [46, p.4] posits that "early cognitive theories typically treated knowing as the manipulation of symbols inside the mind of the individual" while Ernest [29] sees teacher knowledge as a construct that provides a basis for teachers thought processes, before, during and after teaching. A combination of these views This was the view of teacher knowledge adopted for this study. The authors also recognise that teacher knowledge is multifaceted and researchers acknowledge that it is one of the key characteristics of effective teaching [16-17]. This paper indicates that aspects of a teachers' knowledge base also play a central role in facilitating a smooth transition between primary and post-primary mathematics education. This work determines how such levels of knowledge, in domains pertinent to transition, impacts on teachers' approach to teaching and their ability to provide the necessary support to students during the transition period. This study is unique in that it investigates this issue from the perspective of teachers at both sides of the transition, in two different education settings, namely the NI and ROI education systems. The initial step was to develop an appropriate theoretical framework that integrated the issues surrounding transition and teacher knowledge.

\section{Context}

\section{Northern Ireland}

In NI, there are 12 years of compulsory education, seven years in primary and five years in post-primary. Some students also spend an additional two years in post-primary to study for the General Certificate of Education Advanced Level (GCE A-level), or other vocational qualifications, required for entry into further or higher education courses. Children start primary school at four or five years of age, and progress through three stages as depicted in 
Table 1. After Key Stage 2 children transition to post-primary education. Compulsory postprimary education consists of two stages (Table 1).

\section{[TABLE 1 HERE]}

Phased in since September 2007, the NI curriculum promotes a student-centred approach to learning, and places considerable emphasis on the development of skills and capabilities deemed to be important for lifelong learning. Statutory minimum requirements detail the specific aspects of mathematics that should be addressed during Key Stage 2, namely processes in mathematics (mathematical problem solving); number (including some aspects of elementary algebra); measures; shape and space; and handling data [18]. However, the exact content to be covered during each year of Key Stage 2 is not prescribed. In comparison, the statutory requirements for Key Stage 3 have been published in the form of a set of minimum requirements which place considerable emphasis on the skills and capabilities that should be developed. These only briefly refer to the fact that students should acquire knowledge and understanding of number; algebra; shape, space and measures; and handling data [19].

\section{[FIGURE 1 HERE]}

In practice, the actual mathematical curriculum content covered by NI post-primary schools during Key Stage 3 is school-specific, but is usually guided by the requirements outlined in the so-called levels of progression for the statutory teacher-assessed cross-curricular skill of 'Using Mathematics'. Therefore, while there is some alignment between the strands referred to in curricular documents for Key Stage 2 and Key Stage 3, as highlighted in Figure 1, at both phases and perhaps even to a greater extent at Key Stage 3, schools are given considerable autonomy to decide upon the precise mathematical content their students study, and how that content is sequenced. 


\section{Republic of Ireland}

In ROI, education is compulsory between ages six and sixteen, or until a student has completed three years of post-primary education. Students in ROI spend eight years in primary school and, while they are compelled to spend a minimum of three years in post-primary education, the Department of Education and Skills [DES] indicate that the majority of students $(90.6 \%)$ attend for five or six years before progressing to third level education or the workplace. Children in ROI generally commence primary school at four or five years of age. Table 2 shows the different year groups and the typical age of students as they progress through primary school.

Students finish primary education at the end of $6^{\text {th }}$ class, and progress to a post-primary school to continue their education. Post-primary education in the ROI consists of two cycles. Junior Cycle is compulsory for all students and consists of $1^{\text {st }}, 2^{\text {nd }}$ and $3^{\text {rd }}$ year (Table 2). At the end of $3^{\text {rd }}$ year, students in ROI must sit a state examination, known locally as the Junior Certificate. All students are obliged to study mathematics at Junior Cycle. Between the Junior and Senior cycles, students have the option of enrolling in a one-year 'transition year' programme that is available in a large proportion $(81 \%)$ of post-primary schools in ROI [20]. This programme is a non-academic 'gap' year, which seeks to promote students' social and personal development [21]. Students then progress, either directly from Junior Cycle, or from transition year, to Senior Cycle. This is a two-year course of study consisting of $5^{\text {th }}$ and $6^{\text {th }}$ year (Table 2). At the end of the two-year period, students sit another state examination, referred to as the Leaving Certificate, and performance in this is used to determine admission to third level courses.

\section{[TABLE 2 HERE]}

Over the past 20 twenty years, the mathematics curricula for primary and post-primary schools in ROI have changed considerably. In 1999, a revised primary school curriculum was 
introduced, which sought to "enable the child to think and communicate quantitatively and spatially, solve problems, recognise situations where mathematics can be applied, and use appropriate technology to support such applications" [22, p.2]. The primary school mathematics curriculum outlines content objectives for each year of primary education under the five strands of number, algebra, shape and space, measures, and data. Therefore, while primary teachers have autonomy in terms of the pedagogical approaches they employ, and the sequencing of topics, they have little autonomy in relation to the content taught. However, with no formal examination at the end of primary education, this is not always the case and many post-primary teachers report significant differences in the mathematical knowledge, ability and skills that students from different feeder schools possess on entry to post-primary education [23]. In 2010, a revised mathematics curriculum, known as Project Maths, was introduced at post-primary level in ROI. As a constituent element of this revised curriculum, a Common Introductory Course [CIC], consisting of five strands, was introduced for all $1^{\text {st }}$ year students. Four of the five strands central to the CIC are very closely aligned with the primary school mathematics strands, as depicted in Figure 2.

\section{[FIGURE 2 HERE]}

The primary aim of the CIC was to closely align the mathematics curricula that students experience at either side of the transition, but it also sought to avoid the streaming of students by ability level too early in their post-primary education.

\section{Comparing the Jurisdictions}

As this study reports on transition in two different jurisdictions, it is important to highlight at this point the similarities and differences between the two jurisdictions that are pertinent to this study. These are presented in Table 3.

[TABLE 3 HERE] 
The similarities presented in Table 3 highlight that the key transitional periods in a child's educational journey occur at similar ages in both NI and ROI, hence ensuring that there is an opportunity to compare the transition between primary and post-primary mathematics education in these two jurisdictions. The differences, on the other hand, present the authors with possible causes for any differences identified as will be discussed later.

\section{Theoretical Framework}

The framework that underpins this study is that proposed by Anderson et al. [24] and is well validated and utilised by researchers internationally [e.g. 2, 25-26]. This framework outlines the types of discontinuities that typically arise as students transfer from primary to post-primary education and then details the critical factors which allow for smoother transition. However, for the purpose of this study, a new dimension was necessary. This study investigates transition from the perspective of teachers and, in particular, it explores the impact of particular dimensions of teacher knowledge on transition. This dimension needed to be reflected in the theoretical framework. With this in mind, the proposed theoretical framework combined the Anderson model with a model of teacher knowledge, namely Ball et al.'s [28] model of knowledge. This was deemed a suitable model for this paper as it specifically looked at knowledge required for teaching the subject of mathematics and it encapsulates many of the knowledge domains proposed by models designed for post-primary teachers (e.g. Ernest [29]) The adapted theoretical framework for this study is presented in Figure 3.

\section{[FIGURE 3 HERE]}

The aspects of the adapted theoretical framework that are relevant to this research are the:

1. discontinuity pillar as this relates to the gap that currently exists between primary mathematics education and post-primary mathematics education; 
2. support pillar as this is the dimension that recognises the role of teachers in the transition process, and;

3. teacher knowledge pillar as this is one of the factors that helps determine if a teacher has a positive or negative impact on students' transition.

The discontinuities outlined in this model, both social and organisational, were proposed in the work of Anderson et al. [24] and are multifaceted. Their work indicates that as students progress from primary to post-primary education the discontinuities they experience include:

- An increase in school size, both in terms of the physical size of the school building and the number of students enrolled in the school.

- An increase in departmentalisation and streaming at post-primary level.

- Greater emphasis on behaviour with less tolerance for any misdemeanours.

- A shift in focus towards ability and competition as opposed to effort and development.

- A change in relationships with teachers.

The framework subsequently details three concepts that are key to overcoming obstacles and facilitating a more effective transition, namely transitional success/failure, preparedness and support [24]. Of particular relevance to this study is the support domain as it is the domain that details the teachers' role in transition. Anderson et al. [24] outline how support, to augment students' experience of transition, can manifest itself in four different ways (informational; tangible; emotional and social), all of which can, and should be, provided by peers, parents and teachers. However, in order for teachers to offer this support to students the authors hypothesise that it is necessary that they possess the knowledge required for such an undertaking. Hence, the support domain in the theoretical framework for this study is underpinned by particular domains outlined in Ball et al.'s [28] model of knowledge. This model of knowledge extends the work of Shulman [30] who first proposed a model of teacher knowledge consisting of three 
domains - subject matter knowledge; pedagogical knowledge and curricular knowledge. Ball et al.'s [28, p.400] model of knowledge divided subject matter knowledge into three subdomains:

- Common Content Knowledge: Mathematical knowledge required by people across all professions and in every walk of life.

- Horizon Knowledge: This “...is an awareness of how mathematical topics are related over the span of mathematics included in the curriculum" and so requires the teacher to know the mathematics their students have encountered in the past and that which they will encounter in the future [28. p.403].

- Specialised Content Knowledge: Knowledge of mathematics that is unique to the profession of teaching and helps differentiate a teachers' knowledge base from that of a mathematician or layperson. It facilitates the "unpacking of mathematics that is not needed-or even desirable-in settings other than teaching” [28, p.400].

Furthermore, Ball et al. [28] established three different subdomains associated with pedagogical knowledge:

- Knowledge of content and teaching: The knowledge that allows a teacher to combine what they know about teaching with what they know about mathematics (i.e. combining pedagogical and content knowledge).

- Knowledge of content and students: A knowledge that allows teachers to understand students' thought processes, to anticipate what they will find difficult or confusing and to identify where misconceptions may occur.

- Knowledge of content and curriculum: This element of a teacher's knowledge base combines teachers' content knowledge with a knowledge of the curriculum. It requires them to use their own knowledge of mathematics to understand the interrelated nature 
of the mathematics that appears on curricula that their students have already experienced and will experience in the future.

While this model was originally designed to determine the range of knowledge domains needed by primary teachers, there is a significant overlap between this model and other models for teacher knowledge proposed for post-primary teachers e.g. Ernest [29]. As such, the authors propose that one model of teacher knowledge is sufficient to underpin the support dimension for teachers at either side of the transition process. The domains of this model that are particularly pertinent to this study are Horizon Knowledge, Knowledge of Content and the Curriculum and Knowledge of Content and Students]. These domains specifically refer to the need for teachers to possess a broad knowledge of the mathematics curriculum that their students have experienced in the past and will experience in the future, as well as a knowledge of students and the school context. The authors hypothesise that these knowledge domains are critical for effective transition. They support effective teaching whilst also ensuring that teachers are in a position to provide support. This revised model of transition was then employed by the authors in all subsequent stages of the study. It was used to derive the questionnaire for the study and also as a lens to analyse the transition from primary to postprimary mathematics education in both ROI and NI.

\section{Research Questions}

The review of the literature, which clearly outlined the key barriers to successful transition and described the importance of an extensive teachers' knowledge base, in conjunction with the theoretical framework, helped the authors derive the following research questions for this study: 
1. How familiar are $6^{\text {th }}$ class/Year 7 primary school teachers with the teaching methodologies promoted and the syllabus employed in post-primary mathematics and vice versa?

2. What are the consequences of these levels of knowledge in relation to the teaching approaches adopted by post-primary teachers when teaching mathematics to first year post-primary students?

\section{Methodology}

The research design for this study involved the distribution of questionnaires to a representative sample of $6^{\text {th }}$ class and Year 7 teachers in ROI and NI, respectively, as well as $1^{\text {st }}$ Year and Year 8 teachers. The questions contained in the questionnaire reflected the key dimensions from the theoretical framework and sought to investigate if the knowledge possessed by teachers enabled them to offer the support necessary for a smooth transition. To allow for comparison of responses from teachers from both jurisdictions the questionnaires distributed were extremely similar, with the only difference in wording resulting from the differing school contexts in each jurisdiction. Furthermore, the questionnaire distributed to primary teachers closely mirrored that distributed to post-primary teachers. All questionnaires consisted of a mixture of open- and closed-questions and were based on the 'teacher dimension' of the theoretical framework. Four teacher research advisory groups [TRAG] were established to assist with the development of the questionnaire. One TRAG involved three $6^{\text {th }}$ class teachers from ROI; another involved four $1^{\text {st }}$ year teachers from ROI; a third involved two Year 7 teachers from NI; and the final TRAG involved two Year 8 teachers from NI. All teachers involved in the TRAGs were experienced in their positions and were recruited using a purposive sampling method (each teacher was known in a professional capacity by at least one

of the researchers). They were invited to participate based on the expertise they could bring to the research and the contemporary experiences they have in similar peer groups to the research 
participants. Their remit was to advise on the development and distribution of the questionnaires and to provide a key stakeholder perspective to any of the issues raised by the literature. Each member of the TRAG had access to the theoretical framework in advance of the first meeting. Members of the TRAGs also assisted with the piloting of the questionnaire. The survey questions that were relevant to the aims and objectives of this paper are presented in Table 4.

\section{INSERT TABLE 4 HERE}

The sampling frame for the study was all 3,300 primary schools and 723 post-primary schools in ROI along with all 827 primary schools and 202 post-primary schools in NI. The targeted teacher sample size, which allowed for a 5\% margin of error, across each of the education levels, and in both jurisdictions are presented in Table 5, below:

\section{[TABLE 5 HERE]}

By consulting primary TRAGs in both jurisdictions, the authors established that on average, there is one $6^{\text {th }}$ class/Year 7 teacher in each primary school in ROI and NI. As a result, a simple random sample of 700 primary schools in ROI (21.2\% of all primary schools in the jurisdiction) and 450 in NI (54.4\% of all primary schools in the jurisdiction) were selected. Having also consulted post-primary TRAGs in both jurisdictions, it was established that on average, there are two teachers teaching $1^{\text {st }}$ year/Year 8 mathematics in each post-primary school in ROI and NI. Using this estimate, a stratified random sample ${ }^{1}$ of 200 post-primary schools in ROI $(27.7 \%$

\footnotetext{
${ }^{1}$ The strata used in this selection process related to school type in both jurisdictions. There are four different types of post-primary school in ROI and two different types in NI. Hence, the strata used in ROI were secondary schools, comprehensive schools, community colleges and vocational schools while in NI the strata were grammar schools and non-grammar schools
} 
of all post-primary schools in the jurisdiction) and 150 in NI (74.3\% of all post-primary schools in the jurisdiction) were selected.

The questionnaires were distributed to schools in ROI in April 2016 and to NI schools in September of the same year. This decision was made because of the availability of funding and local advice from the TRAGs in both jurisdictions. The primary school questionnaires were sent to the principal of each school and they were asked to distribute it to the $6^{\text {th }}$ class/Year 7 teacher. The pack sent to each of the 1150 principals included an information sheet for their perusal, a teacher information sheet along with the questionnaire and a stamped address envelope $[\mathrm{SAE}]$ for the questionnaires to be returned in. The post-primary questionnaires were sent to the Head of Mathematics in each of the 350 schools and they were asked to distribute the questionnaires to $1^{\text {st }}$ year/Year 8 mathematics teachers. The pack included information sheets for both the Head of Mathematics and the teachers, along with two questionnaires and two SAEs. The information sheets issued to the primary school principals and the post-primary Head of Mathematics invited the recipients to make copies of the questionnaires for additional teachers in their schools, if necessary. Each SAE included in these packs was also given a number corresponding to the school selected so researchers could identify the schools that had not returned the completed questionnaires. Two weeks after sending the questionnaires, follow up telephone calls were conducted in both jurisdictions in a bid to increase the response rate. Upon receipt of the completed questionnaires, the quantitative data was entered and saved into the computer programme SPSS.

\section{Results}

In total 428 primary teachers responded to the questionnaire. 130 of these were based in NI (a response rate of $28.9 \%$ ) while 298 were based in ROI (a response rate of $42.6 \%$ ). 248 postprimary teachers returned surveys. 75 of these taught mathematics in NI (a response rate of $25 \%$ ) and 173 taught mathematics in ROI (a response rate of $43.3 \%$ ). 


\section{Research Question 1}

In order to determine primary teachers' perceived level of curricular knowledge at the transition the primary teachers in the study were surveyed about their levels of familiarity with the $1^{\text {st }}$ year/Year 8 mathematics curricula. The results are presented in Figure 4.

\section{[FIGURE 4 HERE]}

The majority of primary teachers, across both jurisdictions, stated that they were not familiar with the curriculum that their students would be studying the following year. In ROI, 166 teachers $(56.1 \%)$ who responded to this question stated that they were somewhat or highly unfamiliar with the first year mathematics curriculum while 83 NI teachers $(63.8 \%)$ who responded were of a similar disposition. On the other hand, 110 teachers $(37.2 \%)$ in ROI felt they were somewhat or highly familiar with the curriculum on offer in the first year of postprimary school while the corresponding figure for NI was $32(24.6 \%)$.

Figure $3 \underline{4}$ indicates that a higher proportion of NI teachers felt somewhat or highly unfamiliar with the curriculum taught during the first year of post-primary education when compared with their ROI counterparts. However, a Mann Whitney U test indicated the differences between the two jurisdictions were not significant $(U=17191, p>0.05)$.

In addition to investigating primary teachers' level of knowledge of the mathematics curriculum being taught in the first year of post-primary education, this study also sought to ascertain how knowledgeable they were in relation to the teaching strategies that post-primary teachers employ in $1^{\text {st }}$ year/Year 8 . To address this research question, primary teachers were asked to rate their familiarity, again using a 5-point Likert scale, with the teaching methodologies favoured by $1^{\text {st }}$ year/Year 8 teachers. The responses are outlined in Figure 5 .

\section{[FIGURE 5 HERE]}


As was the case when discussing their levels of knowledge relating to the syllabi, the majority of primary teachers also claimed to have deficient levels of knowledge in relation to the pedagogical approaches that their students would be exposed to during the following year of their education. $71.5 \%$ of teachers from ROI and $69.2 \%$ of teachers from NI stated that they were highly or somewhat unfamiliar with the pedagogical approaches employed by their colleagues when teaching $1^{\text {st }}$ year/Year 8 students. On the other hand, less than $1 \%$ of teachers in NI and $4 \%$ of teachers in ROI felt very assured in their levels of knowledge in this regard.

Although a greater percentage of teachers in ROI reported feeling somewhat or highly unfamiliar with the teaching strategies employed in $1^{\text {st }}$ year, a Mann Whitney $U$ test showed that there was no statistically significant difference found between the responses from the two jurisdictions $(\mathrm{U}=18193, p>0.05)$.

Similar questions to those discussed to date were also posed to post-primary teachers to ascertain their levels of knowledge in relation to the mathematics curriculum and pedagogical approaches that their $1^{\text {st }}$ year/Year 8 students would have experienced prior to the transition. The responses received are outlined in Figure 6 and Figure 7.

\section{[FIGURE 6 HERE]}

\section{[FIGURE 7 HERE]}

The results here differ somewhat from those reported by primary teachers. In this case, the majority of NI post-primary teachers $(73.4 \%)$ stated that they were either highly or somewhat familiar with the curriculum that their students would have studied the year previously. Although a considerable number of ROI teachers had a similar outlook (39.9\%), the majority $(52.6 \%)$ still felt highly or somewhat unfamiliar with the content contained on the sixth class curriculum. When surveyed about their levels of familiarity with the pedagogical methods employed by $6^{\text {th }}$ class/Year 7 teachers, $50.6 \%$ of post-primary teachers in NI claimed to be 
highly or somewhat unfamiliar with such approaches while the corresponding figure for the ROI was $76.3 \%$. On the other hand, $33.4 \%$ of NI teachers claimed to be highly or somewhat familiar with these approaches compared with $15.6 \%$ of teachers teaching in ROI.

A Mann Whitney $U$ test was conducted to see if there was a difference in the responses received from the two jurisdictions. The results in relation to teachers' knowledge of the $6^{\text {th }}$ class/Year 7 curriculum indicate that there was a highly significant difference between the responses received from post-primary teachers in NI and those received from post-primary teachers in ROI $(\mathrm{U}=4104, p<0.001)$. Therefore, the difference in the proportion of teachers from NI who stated that they are somewhat or highly familiar with the Key Stage 2 curriculum is statistically significantly greater than the proportion of ROI teachers who said they are somewhat or highly familiar with the $6^{\text {th }}$ class curriculum. Furthermore, there was a highly significant difference noted in relation to teachers' levels of familiarity with the $6^{\text {th }}$ class/Year 7 pedagogical approaches $(\mathrm{U}=4239.5, p<0.001)$. Again, a higher proportion of NI teachers stated that they were somewhat or highly familiar with the approaches used in the final year of primary education and these differences in responses across jurisdictions were statistically significant.

\section{Research Question 2}

The second research question was two-folded and sought to analyse the knock on effect of the perceived gaps in teacher knowledge reported by the teachers in this study. In order to address this research question both groups of teachers were first asked to rate their agreement with the statement "There is a fluid transition between primary and secondary mathematics". The responses received are provided in Figure 8 and Figure 9.

[FIGURE 8 HERE]

[FIGURE 9 HERE] 
Figures 8 and 9 both indicate that a larger proportion of teachers in NI are in agreement with this statement than is the case in ROI. $29.2 \%$ of primary teachers and $37.3 \%$ of post-primary teachers from NI believe there to be a fluid transition between primary mathematics education and post-primary mathematics education. This is compared with $11.5 \%$ of primary and $21.2 \%$ of post-primary teachers in ROI. In order to see if these differences in responses were significant the authors conducted the non-parametric Mann Whitney $U$ test. The difference in responses received were highly significant between both groups of teachers (Primary: $U=$ 14491.5, $p=0.00<0.05$; Post-primary: 5018.0, $p<0.01)$. This again indicates that a significantly higher proportion of NI teachers, at both levels, believe the transition from primary to post-primary mathematics education to be smooth compared to their colleagues in ROI. To further investigate the second research question post-primary teachers were asked to outline the strategy they used when teaching incoming $1^{\text {st }}$ year/Year 8 students. Based on the literature review conducted by the authors, and in conjunction with the advice received from TRAGs, the following were the options that teachers had to choose from when responding to this question:

- I see it as an opportunity for a fresh start and initially assume as little as possible about student knowledge or ability.

- I use the Education Passport ${ }^{2}$ (ROI)/or information from primary schools (NI) to get information on students' prior knowledge and ability.

- I use post-primary entrance test results or my own evaluation test to get information on students' prior knowledge and ability.

- Other (Please describe).

\footnotetext{
${ }^{2}$ In 2014 the Irish Government launched an Education Passport initiative to improve communication between $6^{\text {th }}$ class and $1^{\text {st }}$ year teachers. The overall purpose of the initiative is to help the child experience continuity as they move from primary to secondary education. Primary schools are required to pass documentation onto secondary schools which detail the child's progress and achievement, as well as signalling what support they may need.
} 
Post-primary teachers' responses to this question are outlined in Figure 10.

\section{[FIGURE 10 HERE]}

Figure 10 indicates that the approaches used by mathematics teachers when teaching mathematics to students in their first year of post-primary school differ between the two jurisdictions. For example, in ROI the majority of $1^{\text {st }}$ year post-primary teachers $(68.0 \%)$ stated that they see first year mathematics as an opportunity for a fresh start with students and initially assume very little prior knowledge. On the other hand, only $23.2 \%$ of teachers in NI favoured this approach. Instead, the majority of teachers in NI (47.8\%) stated that they use some form of entrance examination to gauge students' ability and prior knowledge and they design their Year 8 lessons based on the information garnered. Based on the findings presented in Figure 10 , the authors hypothesised that there was a significant difference in the responses from the two regions. To test this, a Chi Square test ${ }^{3}$ was conducted, as the data in this instance was not ordinal. This test indicated a significant association between school jurisdiction and the teaching approach favoured with incoming $1^{\text {st }}$ year or Year 8 students $\left[\chi^{2}(3, n=238)=45.781\right.$, $p=0.00$, Cramer's V $=0.44]$. According to Cohen (1988) the Cramer's V result indicates that the independent variable (jurisdiction) has a medium impact on the dependent variable (approach to teaching first year/Year 8).

\section{Discussion}

Transition from primary to post-primary mathematics has been linked to declines in students' attitudes towards mathematics and their mathematical achievements [11,31-33]. Due to such findings, the authors were keen to unearth potential causes for the problems that arose during this transition and so investigated the role that certain dimensions of teacher knowledge can play in the transition. The first research question underpinning this study required the authors

\footnotetext{
${ }^{3}$ When conducting the Chi Square test the authors noted that the expected cell count was sufficiently high for more than $80 \%$ of cells.
} 
to investigate how familiar $6^{\text {th }}$ class/Year 7 teachers were with the post-primary mathematics syllabus and the teaching methodologies promoted at post-primary level and vice versa. The results of this study suggest that primary teachers, in both jurisdictions, do not possess an indepth knowledge of the curriculum and teaching strategies employed during the subsequent phase of education. Almost two-thirds of all primary teachers surveyed in NI (63.8\%) as well as over half those surveyed in ROI (56.1\%) stated that they were highly or somewhat unfamiliar with the Year $8 / 1^{\text {st }}$ year curriculum. These proportions rose when these teachers were questioned about their knowledge of the pedagogical approaches employed in the following year of schooling. $70.3 \%$ of NI primary teachers and $72.4 \%$ of ROI primary teachers stated that they were highly or somewhat unfamiliar with the teaching methods recommended for use in the first year of post-primary education. These findings indicate that teachers, in both jurisdictions, do not possess some of the key knowledge domains that were deemed necessary by Ball et al. [28]. For example, teachers in this study do not appear to possess high levels of Horizon Knowledge or Knowledge of Content and Curriculum or Knowledge of Content and Students, three domains which were central to the model proposed by Ball et al. [28]. According to Ball \& and Bass [34, p.1] horizon knowledge is defined as "...a kind of mathematical 'peripheral vision' needed in teaching, a view of the larger mathematical landscape..." and this study provides evidence that $6^{\text {th }}$ class/Year 7 teachers simply do not have this 'peripheral vision' or curriculum knowledge [29]. This is corroborated by Mosvold and Fauskanger [35] who found that teachers in their study did not possess a strong understanding of the mathematics on the horizon as such knowledge was not held in high regard. According to Zazkis and Mamolo [36], knowledge of the mathematical horizon affects the pedagogical choices that a teacher makes and limited knowledge in this area, as reported by teachers in this study, can affect the approach teachers adopt when teaching mathematics in the final year of primary school. Furthermore, the theoretical framework underpinning this study indicates that 
teacher knowledge plays a key role in the support that primary and post-primary teachers can offer during the transition period. Hence, the authors conclude that deficient levels of horizon knowledge/knowledge of content and curriculum on the part of teachers, as demonstrated here, may have a detrimental impact on students' experience of transition as teachers will not be in a positon to support students as they progress from one educational phase to the next. Such support was a critical aspect of the pathway for a smoother transition outlined in this study's theoretical framework.

When post-primary teachers were questioned in relation to their knowledge of the curriculum and pedagogical approaches adopted in the last year of primary school, the majority of ROI teachers indicated that they were highly or somewhat unfamiliar with both the curriculum and the pedagogical approaches employed. This was in line with the findings of Smyth et al. [37] who reported that only half of post-primary teachers are familiar with the primary curriculum. According to the National Council for Curriculum and Assessment [NCCA] [38], failure to understand what and how students learn in primary school can lead to students becoming confused as they enter post-primary education, meaning that the low levels of horizon knowledge reported by teachers in this study will undoubtedly affect student's experience of transition between the two phases. However, the situation in NI was significantly different. In NI only $25.3 \%$ of teachers reported being highly or somewhat unfamiliar with the Year 7 curriculum while $50.6 \%$ of those surveyed stated that they were highly or somewhat unfamiliar with the pedagogical approaches employed. The results showed that there was a significant difference in the perceived levels of horizon knowledge between post-primary teachers in ROI and those teaching in NI. As a result, the authors anticipate that NI post-primary teachers are better equipped to support students through the transition process and they sought to identify why this significant difference existed. 
To help eradicate some of the obstacles associated with the transition from primary to postprimary education, Sutherland et al. $[39$, p.6] recommended "...barriers should be removed at national and local level to enable the joint training, development and support of primary and secondary teachers, especially those who work with pupils around transition from primary to secondary school." Such a training programme was available to teachers in NI from 2015 but no such programme was offered to teachers in the ROI. The Continuous Professional Development [CPD] programme in NI was established to address issues surrounding the transition from primary to post-primary school and to provide teachers of mathematics in both phases with high-quality professional learning experiences to promote the development of cross-phase curricular and pedagogical knowledge and skills. Between January 2015 and June 2016, a two-day programme was offered to post-primary mathematics teachers, and two halfday training sessions were offered to primary school teachers in NI.

The findings of this study, which showed statistically significant differences in the levels of horizon knowledge of NI and ROI post-primary mathematics teachers, suggest that the initial stage of the NI CPD project has led to beneficial effects in terms of post-primary teachers' levels of familiarity with the content and pedagogical approaches employed in the final year of primary schooling. On the other hand, the authors acknowledge that similar benefits were not apparent in relation to primary teachers' horizon knowledge, as there were no significant differences at this level between the two jurisdictions. However, it is important to note that, during the initial stage of the CPD project, the professional development of post-primary teachers was prioritised and it was only in the 2016-17 academic year that the focus of the CPD project shifted to the provision of cross-phase CPD. So, while the authors cannot say with certainty that the CPD programme was the sole reason for the differences reported between the two jurisdictions, there are positive indicators to suggest it helped NI post-primary mathematics teachers to develop a deeper knowledge of the curriculum and pedagogical approaches 
employed in the final year of primary education, thus giving them an advantage over their ROI colleagues. The authors recommend that this programme is officially evaluated in the near future to determine exactly what contribution, if any, it made to improvements in teachers' levels of horizon knowledge in NI. If it is found to play a significant role in improving teachers' levels of horizon knowledge, then this programme should act as a model for CPD for teachers at either side of the transition internationally.

The second research question sought to investigate the ramifications of teachers' levels of knowledge on the teaching approaches adopted by post-primary teachers. Research has shown that deficient levels of horizon knowledge limit the pedagogical choices available to teachers [36]. The main finding to emerge from this study was in relation to the different approaches employed to teach students in their first year of post-primary mathematics by teachers in the two jurisdictions. NI teachers, who reported high levels of horizon knowledge, were mainly in favour of using entrance examinations and building on the knowledge demonstrated by students in this assessment when designing their Year 8 classes. It would be anticipated that such an approach, which involves building on the knowledge students developed in primary school, would challenge students as they progressed between the phases and this challenge is something that has been deemed necessary by researchers internationally [40-41]. On the other hand, ROI teachers, who reported low levels of horizon knowledge, were, for the most part, in favour of treating $1^{\text {st }}$ year as a "fresh start" and assuming as little as possible about students' prior knowledge. This corroborated the findings of the NCCA [38] who found that almost onethird of Irish students reported that several first year subjects involved repetition of the content studied at primary school. This repetitive approach, coined the "tabula rasa" approach, has been found to have a negative impact on students' as they transition from primary to post-primary education internationally [3]. Galton et al. [15] found that this "fresh start" approach led to boredom in students competent in the material and disillusionment among students who had 
struggled with the material originally. Other researchers also indicated that such an approach could lead to both confusion and disengagement thus affecting students' attitudes and commitment to mathematics during the transition process [42]. The authors hypothesise that the approach favoured by ROI post-primary teachers is a consequence of these teachers' selfreported, lack of knowledge of the curriculum and pedagogical approaches employed in the previous educational phase. The authors posit that only when teachers fully understand the content and pedagogical approaches that their students were exposed to previously will they be able move away from the tabula rasa approach, which disregards prior learning, and adopt an approach that builds on the progress their students have made to date in an engaging and motivating manner as promoted by Evangelou et al. [5].

\section{Conclusion}

This research focused on school transitions, primarily between the ages of 11 and 14, whereby students move from primary to post-primary education. Many studies have previously acknowledged the impact that this particular transition can have on students' attitudes and attainment in mathematics [11,31-33]. The theoretical framework which underpinned this study outlined the role that teachers play in the transition and their support is seen as one of the cornerstones of successful or smooth transitions. However, teachers can only provide such support if, as the framework suggests, they have the knowledge required to ensure curricular and pedagogical continuity. Hence, this study sought to investigate the self-reported levels of knowledge of teachers at either side of the transition and to determine how such knowledge impacts on their approach to teaching. While the research was undertaken in two neighbouring jurisdictions on the island of Ireland, the findings are of significance internationally as successful transition is an educational goal in many counties around the world [14,43-44]. However, the research is particularly timely and relevant in the Irish context as one of the 
Government objectives in the 'Action Plan for Education 2017' is to improve the transition of learners at critical stages in the education system [45].

This study combined Anderson et al.'s [24] model of transition with a model of teacher knowledge to design a theoretical framework that informed the research instrument and provided a lens for analysing transition in mathematics education. The results highlighted how the majority of teachers, with the exception of NI post-primary teachers, reported low levels of knowledge in relation to the curriculum and pedagogical approaches being adopted in the previous/subsequent phase of education. These low levels of knowledge meant that teachers were not in a position to support students through the transition process and that post-primary teachers in the ROI were compelled to adopt an approach to teaching that involved the repetition of prior learning. Research has indicated that such an approach tends to lead to boredom and disengagement. Such repercussions would undoubtedly lead to discontinuities as the students progressed from one education phase to the next.

The authors strongly recommend that action needs to be taken to help ensure a smoother transition internationally and one possible approach is to ensure teachers at both levels become familiar with each other's curricula. Teachers are not to blame for the deficient levels of knowledge reported in this study as many, particularly in ROI, have never been given the opportunity to explore and develop the aforementioned knowledge domains which can contribute to a smooth transition. To address this, the authors suggest that the CPD programme employed in NI is formally evaluated and, if shown to impact on teachers' levels of knowledge, it should act as an exemplar for other CPD initiatives that seek to improve horizon knowledge among teachers at either side of the primary to post-primary transition. The authors also recommend that time is allocated in the school year to events that promote communication and collaboration between teachers at either side of the crossing. Relationships must be encouraged between local post-primary schools and their feeder primary schools. Such initiatives will help 
teachers further develop their knowledge in the critical domains outlined in this paper. It will allow primary teachers to become more familiar with the mathematics that students will learn at post-primary level while simultaneously ensuring post-primary teachers develop the knowledge required to build on the skills, knowledge and attributes which the learner has developed in the preceding phase. The authors firmly believe that the actions outlined here will help to improve teacher knowledge and this in turn will enable teachers to support students in the transition process. Only when teachers are in a position to offer such support will issues surrounding the transition be somewhat overcome and in turn the actions recommended here will help to ensure greater continuity and improve the fluidity of transitions from primary to post-primary mathematics education.

\section{References}

[1] Zeedyk MS, Gallacher J, Henderson M, et al. Negotiating the transition from primary to secondary school: Perceptions of pupils, parents and teachers. Sch Psychol Int. 2003; 24(1): $67-79$.

[2] West P, Sweeting H, Young R. Transition matters: Pupils' experiences of the primarysecondary school transition in the West of Scotland and consequences for well-being and attainment. Res Pap Educ. 2010; 25:21-50.

[3] Bicknell B, Burgess T, Hunter R. Explorations of Year 8 to Year 9 transition in mathematics. Findings from the New Zealand Numeracy Development Projects. Wellington, New Zealand: Learning Media Limited; 2009. p.145-157.

[4] Barber M. Bridges to assist a difficult crossing. Times Educational Supplement [Internet]. 1999 Mar [cited 2018 Mar]. Available from: https://www.tes.com/news/tes-archive/tespublication/bridges-assist-a-difficult-crossingopinion.

[5] Evangelou M, Taggart B, Sylva K, et al. Effective pre-school, primary and secondary education 3-14 project (EPPSE 3-14): What makes a successful transition from primary to secondary school? Nottingham: DfES Publications; 2008.

[6] Elkins J. Literacy and the transition to secondary school. Aust J Read. 1989; 12(4):300305.

[7] Green P. Moving from the world of the known to the unknown: The transition from primary to secondary school. Melb Stud Ed. 1997; 38(2):67-83.

[8] Tilleczek K. Building bridges: Transitions from elementary to secondary school. Ed Can. 2008; 48(1):68-71. 
[9] Tossavainen T, Juvonen A. Finnish primary and secondary school students' interest in music and mathematics relating to enjoyment of the subject and perceptions of the importance and usefulness of the subject. Res Stud in Mus Ed. 2015; 37(1): 107-121.

[10] Hernandez-Martinez P, Williams J, Williams J, et al. Students' views on their transition from school to college mathematics: Rethinking 'transition' as an issue of identity. Res Math Ed. 2011; 13(2):119-130.

[11] Grootenboer P, Marshman M. Mathematics, affect and learning: Middle school students' beliefs and attitudes about mathematics education. Singapore: Springer; 2016.

[13] Attard C. (2010). Students' experiences of mathematics during the transition from primary to secondary school. In: Sparrow L, Kissane B, Hurst C, editors. Proceedings of the 33rd annual conference of the Mathematics Education Research Group of Australasia: Shaping the Future of Mathematics Education; 2010 Jul 3-7; Freemantle, Australia: MERGA. p. 67-74.

[14] Paul M. Managing the transition from primary school mathematics to secondary school mathematics: teachers' and learners' perspectives. Mediter J Soc Sci. 2014; 5(25):205-215.

[15] Galton MJ, Gray J, Ruddick J. The impact of school transitions and transfers on pupil progress and attainment, London: DfEE; 1999.

[16] Shulman LS. On teaching problem solving and solving the problems of teaching. In Silver EA, editor. Teaching and learning mathematical problem solving: Multiple research perspectives. New Jersey (NJ): Laurence Erlbaum; 1985. p.439-450

[17] Ball DL, Hill HC, Bass H. Knowing mathematics for teaching: Who knows mathematics well enough to teach third grade, and how can we decide. Paper presented at: Annual Meeting of the American Educational Research Association; 2005 Apr 11-15; Montreal, Canada.

[18] Council for the Curriculum, Examinations and Assessment. Statutory requirements for mathematics and numeracy at key stage 2. Belfast, Northern Ireland: CCEA; 2014a.

[19] Council for the Curriculum, Examinations and Assessment. Statutory requirements for mathematics with financial capability at key stage 3. Belfast, Northern Ireland: CCEA; 2014b.

[20] Authors. Eur J of Sci Math Ed. 2016

[21] Clerkin A. Personal development in secondary education: The Irish Transition Year. Ed Policy Anal Arch. 2012; 20(38):1-20.

[22] Department of Education and Skills. Primary school curriculum: Mathematics. Dublin, Ireland: The Stationary Press; 1999.

[23] Authors. Issues in Educational Research (2019)

[24] Anderson LW, Jacobs J, Schramm S, et al. School transitions: Beginning of the end or a new beginning? Int J Ed Res. 2000; 33(4): 325-339.

[25] Sirsch U. The impending transition from primary to secondary school: Challenge or threat? Int J Behav Dev. 2003; 27(5):385-395.

[26] Cauley KM, Jovanovich D. Developing an Effective Transition Program for Students Entering Middle School or High School. The Clgh. 2006; 80(1):15-25.

[28] Ball DL, Thames MH, Phelps G. Content knowledge: What makes it special? J Teach Ed. 2008; 59(5):389-407. 
[29] Ernest P. The knowledge, beliefs and attitudes of the mathematics teacher: a model. J Ed Teach. 1989; 15(1):13-33.

[30] Shulman L. Those who understand: Knowledge growth in teaching. Ed Res. 1986; 15(2):4-14.

[31] Attard C. If I had to pick any subject, it wouldn't be maths: Foundations for engagement with mathematics during the middle years. Math Ed Res J. 2013; 25(4):569-587.

[32] Carmichael C. Transitioning to secondary school: The case of mathematics. Aust J Ed Dev Psychol. 2015; 15:13-23.

[33] Martin AJ, Way J, Bobis J, et al. Exploring the ups and downs of mathematics engagement in the middle years of school. J Early Adolesc. 2015; 35(2):199-244.

[34] Ball DL, Bass H. With an eye on the mathematical horizon: Knowing mathematics for teaching to learners' mathematical futures. Paper presented at: $43^{\text {rd }}$ Jahrestagung für Didaktik der Mathematik; 2009 Mar 1-4; Oldenburg, Germany.

[35] Mosvold R, Fauskanger J. Teachers' beliefs about mathematical horizon content knowledge. Int J Maths Teach Learn. 2014; 9(3):311-327.

[36] Zazkis R, Mamolo A. Reconceptualizing knowledge at the mathematical horizon. For Learn Math. 2011; 31(2):8-13.

[37] Smith E, Mc Coy S, Darmody M. Moving up: The experiences of first-year students in post-primary education. Dublin: Liffey Press Dublin; 2004.

[38] National Council for Curriculum and Assessment. Review of mathematics in post-primary education: Discussion paper. Dublin, Ireland: NCCA; 2005.

[39] Sutherland R, Ching Yee W, McNess E, et al. Supporting learning in the transition from primary to secondary schools. Bristol: Merchant Venturers; 2010.

[40] Turner J. Unfinished business: putting motivation theory to the "classroom test". In Karabenick S, Urdan TC editors. Decade ahead: Application and contexts of motivation and achievement Vol. 16, Part B. Bradford, UK: Emerald Group Publishing Limited; 2010

[41] Hernandez-Martinez P, Williams J. Against the odds: Resiliance in mathematics students in transition. Brit Ed Res J. 2013; 39(1):45-59.

[42] Bicknell B, Hunter R. School transition from Year 6 to Year 7: A focus on mathematics. Int J Math Teach Learn. 2012 [cited 2018 Sept] [18 p.] http://www.cimt.org.uk/journal/.

[43] Topping K. Primary-secondary transition: Differences between teachers' and children's perceptions. Improv Sch.2011; 14(3):268-285.

[44] Hopwood B, Hay I, Dyment J. The transition from primary to secondary school: Teachers' perspectives. Aust Ed Res. 2016; 43(3):289-307.

[45] Department of Education and Skills. Action Plan for Education 2017. Dublin, Ireland: DES; 2017.

[46] Putnam R.T, Borko, H. What do views of knowledge and thinking have to say about research on teacher learning. Ed Res; 29(1):4-15 